\title{
Hygrothermal performance of timber-concrete composite panels - theoretical investigation
}

\author{
Viktória Bajzecerová, ${ }^{1, *}$, Eva Kormaníková ${ }^{1}$ and Ján Kanócz ${ }^{2}$ \\ ${ }^{1}$ Faculty of Civil Engineering, Institute of Structural Engineering, Technical University of Košice, \\ Slovakia \\ ${ }^{2}$ Faculty of Art, Department of Architecture, Technical University of Košice, Slovakia
}

\begin{abstract}
The concrete layer as a part of the timber-concrete composite (TCC) element makes it possible to maintain the accumulated heat and thus reduce the energy required for heating. Especially for buildings used for a sauna, swimming pools or wellness. In the TCC cross-section due to uneven thermal and humidity deformation of both materials, additional stresses occur. It can lead to the failure of partial cross-sections or composite connection. The aim of the research is to investigate the influence of changing humidity and temperature conditions of the environment on the composite adhesively bonded TCC panels without the influence of other phenomena such as mechanical stress or the effect of concrete shrinkage. The paper presents the results of the preliminary theoretical investigation before the realization of measurements on prepared specimens.
\end{abstract}

\section{Introduction}

The timber-concrete composite (TCC) structural elements have many advantages such as the higher stiffness and load-bearing capacity, lower vibration compared to the timber ceiling. From the point of view of non-structural advantages, the accumulation ability of these elements seems to be very significant in comparison with common structural elements of wooden buildings. The concrete layer in the TCC element makes it possible to retain the accumulated heat and thus reduce the energy required for heating, especially of buildings with wellness, sauna or swimming pools. The use of TCC panels as structural elements of roofs and walls could reduce the cost of heating such spaces.

When using TCC elements in an environment with changing humidity and temperature conditions, it is important to know the behavior of these elements with respect to different coefficients of thermal and humidity expansion of both components and especially the different deformations in each direction due to orthotropic behavior of timber [1, 2, 3]. Due to uneven thermal and humidity deformations of each layer of TCC, normal stress occurs, which can lead to the partial cross-section defect or the shear connection failure. The influence of humidity and temperature changes on the behavior of TCC beams with an adhesive shear connection was studied within various long-term bending tests $[4,5]$. The

\footnotetext{
* Corresponding author: viktoria.bajzecerova@tuke.sk
} 
results show a significant influence humidity and temperature conditions on the deflection of the TCC over time.

The aim of the ongoing research is to investigate the influence of changing humidity and temperature conditions of the environment on the TCC multilayer panels from various types of timber parts (vertically or cross-laminated timber) and various stiffness of shear connections (adhesive, screws, grooves). The specimens will be placed in an airconditioned chamber and exposed to an environment with varying relative humidity and temperature. The aim is to investigate the influence of the environment without mechanical stress and the effect of concrete shrinkage.

This paper presents parameters of preliminary test specimens and a calculation model for orthotropic multilayer composite members. The estimated stresses and deformation values, which can occur due to a special range of thermal and humidity changes, are presented. The results will serve as a base for the choice and calibration of measuring equipment.

\section{Parameters of specimens}

Three specimens of TCC panels were prepared. The width and length of the specimens are $300 \mathrm{~mm}$ and $750 \mathrm{~mm}$, respectively (Figure 1a). The timber part consists of vertical laminated glued timber with a depth of $80 \mathrm{~mm}$, the concrete layer depth is $50 \mathrm{~mm}$. The bonding agent Sikadur 32 [6] was used for bonding fresh concrete (Figure 1b). The rigid bonding of TCC panels eliminates the effect of connection compliance on the deformation of panels within the experiment. The specimens were stored for two years in the laboratory. The drying shrinkage of the concrete will not affect the results at the time of the experiment. The specimens will be placed in an air-conditioned chamber and exposed to an environment with varying relative humidity of $50 \%$ to $90 \%$ and a temperature of $10^{\circ} \mathrm{C}$ to $40^{\circ} \mathrm{C}$. The strains will be measured by gauges placed on the top of the concrete and timber surface and on the bottom of the timber part in both directions.
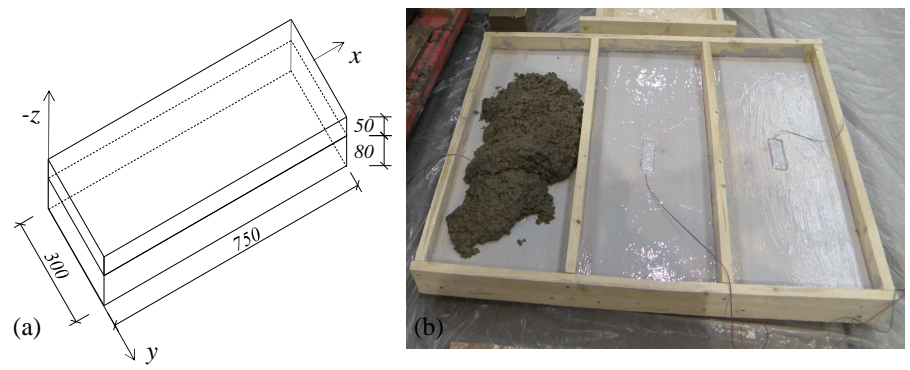

Fig. 1. a) Geometrical parameters of specimens; b) Preparation of specimens.

Modulus of elasticity $\left(E_{\mathrm{x}, 1}=E_{\mathrm{y}, 1}\right)$, cylinder compressive strength and axial tensile strength of concrete were determined according to [7] with the values of $26 \mathrm{GPa}, 55 \mathrm{MPa}$ and 8.1 MPa, respectively. The coefficient of thermal expansion $\alpha_{\mathrm{T}, 1}$ and Poisson's ratio of concrete was considered with a value of $1.10^{-5}$ and 0.18 according to [8].

Modulus of elasticity (MOE) $E_{\mathrm{x}, 2}$ and bending strength of timber parallel to the grain were determined according to [9] with the value of $13.9 \mathrm{GPa}$ and $50 \mathrm{MPa}$, respectively. The MOE of timber perpendicular to the grain $E_{\mathrm{y}, 2}$ was determined according to [10] as $E_{\mathrm{x}, 2} / 30$ with the value of $0.463 \mathrm{GPa}$. The coefficient of thermal expansion $\alpha_{\mathrm{Tx}, 2}, \alpha_{\mathrm{Ty}, 2}$ of timber was considered with a value of $5.10^{-6}$ in both directions. Coefficient of humidity expansion $\alpha_{\mathrm{ux}, 2}$ and $\alpha_{\mathrm{uy}, 2}$ of timber was considered with values $3.10^{-3}$ and 0.15 , respectively. The value of the Poisson's ratio of timber $v_{\mathrm{xy}, 2}$ was taken with a value of 0.2 . 


\section{Calculation model}

\subsection{Stress-strain distribution by uniaxial behavior}

For the purpose of illustrating the behavior of a multilayer panel with a mismatch of thermal and humidity expansion coefficient of each layer, let's consider a composite member with $n$ layers according to Figure 2 with different mechanical properties and different coefficient of thermal and humidity expansion. Layers are bonded together.

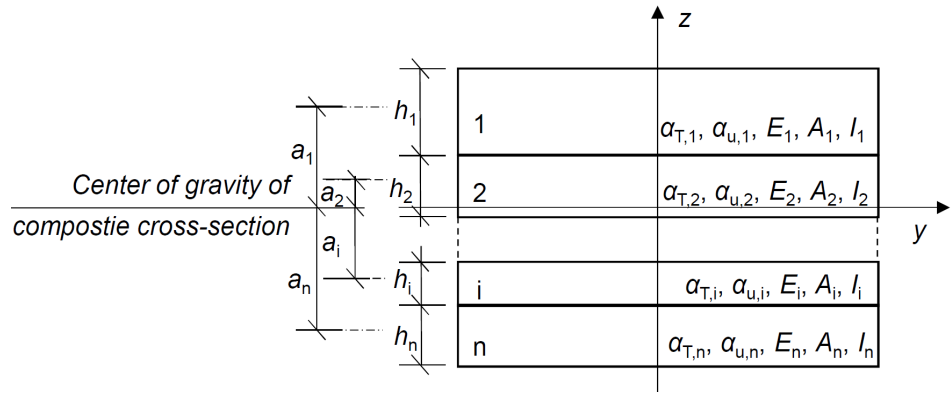

Fig. 2. The multilayer composite cross-section with mismatch of thermal and humidity expansion coefficient.

When changing humidity and temperature conditions of the environment, each layer will contract or extend accordingly to their coefficient of thermal and humidity expansion. Different expansion coefficients cause the different thermal and humidity strains values of each layer. The constrained deformation of bonded layers causes the internal stresses and strains in composite cross-section. The total strain of i-layer is the sum of the thermal $\varepsilon_{i}^{\mathrm{T}}$ and humidity strain $\varepsilon_{\mathrm{i}}^{\mathrm{u}}$ of i-layer and the elastic strain $\varepsilon_{\mathrm{i}}^{\mathrm{el}}$ due to constrained expansion or contraction of all bonded layer

$$
\varepsilon_{\mathrm{i}}=\varepsilon_{\mathrm{i}}^{\mathrm{el}}+\varepsilon_{\mathrm{i}}^{\mathrm{T}}+\varepsilon_{\mathrm{i}}^{\mathrm{u}},
$$

where $\varepsilon_{\mathrm{i}}^{\mathrm{T}}=\alpha_{\mathrm{i}, \mathrm{T}} \Delta T, \varepsilon_{\mathrm{i}}^{\mathrm{u}}=\alpha_{\mathrm{i}, \mathrm{u}} \Delta u$, and $\varepsilon_{\mathrm{i}}^{\mathrm{el}}=\varepsilon_{\mathrm{i}}^{\mathrm{F}}+\varepsilon_{\mathrm{i}}^{\mathrm{M}}, \alpha_{\mathrm{i}, \mathrm{u}}$ is moisture expansion coefficient of $\mathrm{i}$ layer; $\Delta u$ - change of moisture content of i-layer; $\alpha_{\mathrm{i}, \mathrm{T}}$ - thermal expansion coefficient of $\mathrm{i}$ layer; $\Delta T$ - temperature changes of i-layer.

The wood reaches an equilibrium of moisture condition by placing long enough in an environment with constant parameters. The equilibrium of moisture content was determined according to [11]:

$$
u_{R H}=\frac{0,01 \cdot R H}{-0,00084823 \cdot R H^{2}+0,11665 \cdot R H+0,38522},
$$

where $R H$ is the relative humidity of the environment in $\%$.

Temperature changes of the environment are reflected with temperature changes at each point of the cross-section according to the heat equations. For simplicity, the temperature of the timber and the concrete equal to the environment temperature were considered.

Components of elastic strain $\varepsilon_{\mathrm{i}}^{\mathrm{el}}$ are:

$$
\varepsilon_{\mathrm{i}}^{\mathrm{M}}=\kappa\left( \pm \frac{h_{\mathrm{i}}}{2}+a_{\mathrm{i}}\right),
$$




$$
\varepsilon_{\mathrm{i}}^{\mathrm{N}}=\frac{\sum_{i=1}^{n}\left(\varepsilon_{\mathrm{i}}^{\mathrm{T}}+\varepsilon_{\mathrm{i}}^{\mathrm{u}}\right) E_{\mathrm{i}} A_{\mathrm{i}}}{\sum_{i=1}^{n} E_{\mathrm{i}} A_{\mathrm{i}}}-\left(\varepsilon_{\mathrm{i}}^{\mathrm{T}}+\varepsilon_{\mathrm{i}}^{\mathrm{u}}\right),
$$

where curvature $\kappa$ of the multilayer composite member due to inelastic strains of each layer is:

$$
\kappa=\frac{\sum_{i=1}^{n}\left(\varepsilon_{\mathrm{i}}^{\mathrm{T}}+\varepsilon_{\mathrm{i}}^{\mathrm{u}}\right) E_{\mathrm{i}} A_{\mathrm{i}} a_{\mathrm{i}}}{\sum_{i=1}^{n} E_{\mathrm{i}} I_{\mathrm{i}}+E_{\mathrm{i}} A_{\mathrm{i}} a_{\mathrm{i}}^{2}},
$$

$E_{\mathrm{i}}$ - modulus of elasticity; $I_{\mathrm{i}}$ - moment of inertia of i-layer, $A_{\mathrm{i}}$ - cross-section area of i-layer; $a_{\mathrm{i}}$ - distance of gravity of i-layer from the centre of gravity of composite cross-section; $h_{\mathrm{i}}$ depth of i-layer.

The normal stress of i-layer is:

$$
\sigma_{\mathrm{i}}=E_{\mathrm{i}} \varepsilon_{\mathrm{i}}^{\mathrm{el}} .
$$

In the calculation, the elastic strains $\varepsilon_{\mathrm{i}}^{\mathrm{el}}$ of the individual layers were limited by the respective material limit strains resulted from strength properties.

\subsection{Stress-strain distribution by biaxial behavior}

Let's consider a composite member with $n$ layers according to Figure 1 with the bending in two orthogonal axis $x$ and $y$. The normal direction of the free-surfaces of the member is in the $z$-axis. The stress-strain relationship can be express as:

$$
\left\{\begin{array}{l}
\varepsilon_{\mathrm{x}}^{\mathrm{el}} \\
\varepsilon_{\mathrm{y}}^{\mathrm{el}}
\end{array}\right\}=\left[\begin{array}{cc}
\frac{1}{E_{\mathrm{x}}} & -\frac{v_{\mathrm{yx}}}{E_{\mathrm{y}}} \\
-\frac{v_{\mathrm{xy}}}{E_{\mathrm{x}}} & \frac{1}{E_{\mathrm{y}}}
\end{array}\right] \cdot\left\{\begin{array}{l}
\sigma_{\mathrm{x}} \\
\sigma_{\mathrm{y}}
\end{array}\right\},
$$

where

$$
v_{\mathrm{xy}}=\frac{E_{\mathrm{x}}}{E_{\mathrm{y}}} v_{\mathrm{yx}}
$$

\subsection{Deflection of the n-layer panel}

The deflection of the composite panel with a length of $L_{\mathrm{x}}$ in direction of $x$-axis and $L_{\mathrm{y}}$ in direction of $y$-axis affected by the humidity and thermal changes of the environment was for the simplicity calculated as a sum of deflection in both direction

$$
\delta=\kappa_{\mathrm{x}} \frac{L_{\mathrm{x}}^{2}}{8}+\kappa_{\mathrm{y}} \frac{L_{\mathrm{y}}^{2}}{8}
$$

where $\kappa_{\mathrm{x}}$ and $\kappa_{\mathrm{y}}$ is the curvature of the panel in respective direction according to the equation (5). 


\section{Results and discussion}

Figures 3 and 4 show calculated values of normal stress in the timber-concrete composite panels due to changes of relative humidity $(\mathrm{RH})$ in the range of $50 \%$ to $90 \%$ and temperature (T) in the range of $10^{\circ} \mathrm{C}$ to $40^{\circ} \mathrm{C}$. In the calculation, environmental changes are related to the $\mathrm{T}$ of $10^{\circ} \mathrm{C}$ and $\mathrm{RH}$ of $50 \%$. In the graphs, maximal and minimal calculated values of stress on the top and bottom surface of the partial cross-section for the considered range of $\mathrm{T}$ and $\mathrm{RH}$ are pointed out.

Temperature increase causes the elongation of the timber and concrete part of the specimen in both directions, but the higher value of thermal expansion of concrete causes the rise of tension stress in the top surface of both concrete and timber. Conversely, in the bottom surfaces, the rise of compressive stress occurs.

The rise of the relative humidity of environment cause elongation of the timber part, but with different values in $x$ and $y$-direction. The considered value of the coefficient of humidity expansion parallel to grain (in the $x$-direction) is only $2 \%$ of the value for perpendicular to the grain (in the $y$-direction). High values of timber strain due to humidity changes in $y$-direction cause very high values of tensile stress in the concrete part. When the relative humidity of the environment is increased by $10 \%$, in the concrete part, limit elastic deformations in the $y$-direction and thus cracking are expected. Further increase in the relative humidity should no longer cause an increase in the elastic strains and stresses in the $y$-direction of composite specimens (Figure 4).

The range of the calculated values of deflection was -0.108 to $1.181 \mathrm{~mm}$. The values can be measured using a sensitive device. The experiment will focus on measuring strains on the surface of specimens and on the top surface of the timber part in the $x$-direction. The results of the experiment and numerical analysis will be compared.
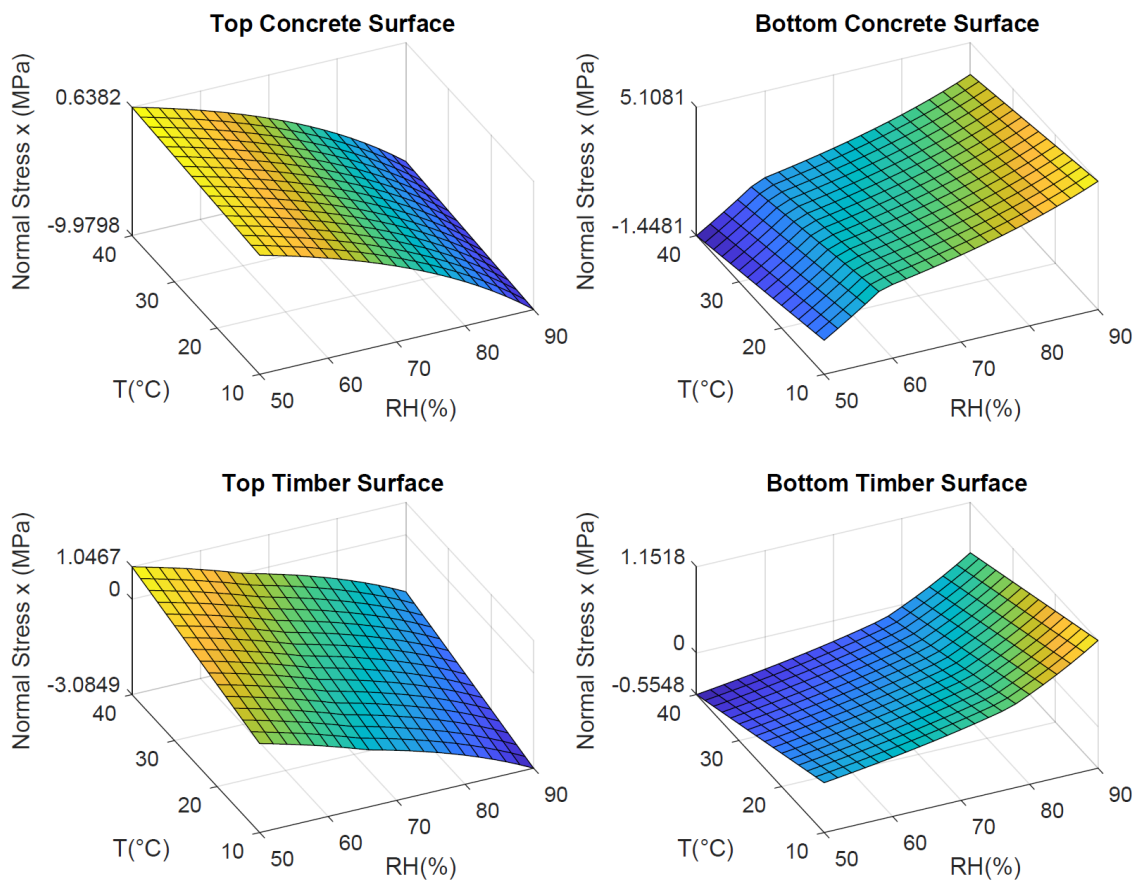

Fig. 3. Normal stress in timber-concrete composite cross-section in $x$-direction due to thermal $(\mathrm{T})$ and humidity $(\mathrm{RH})$ changes of the environment. 

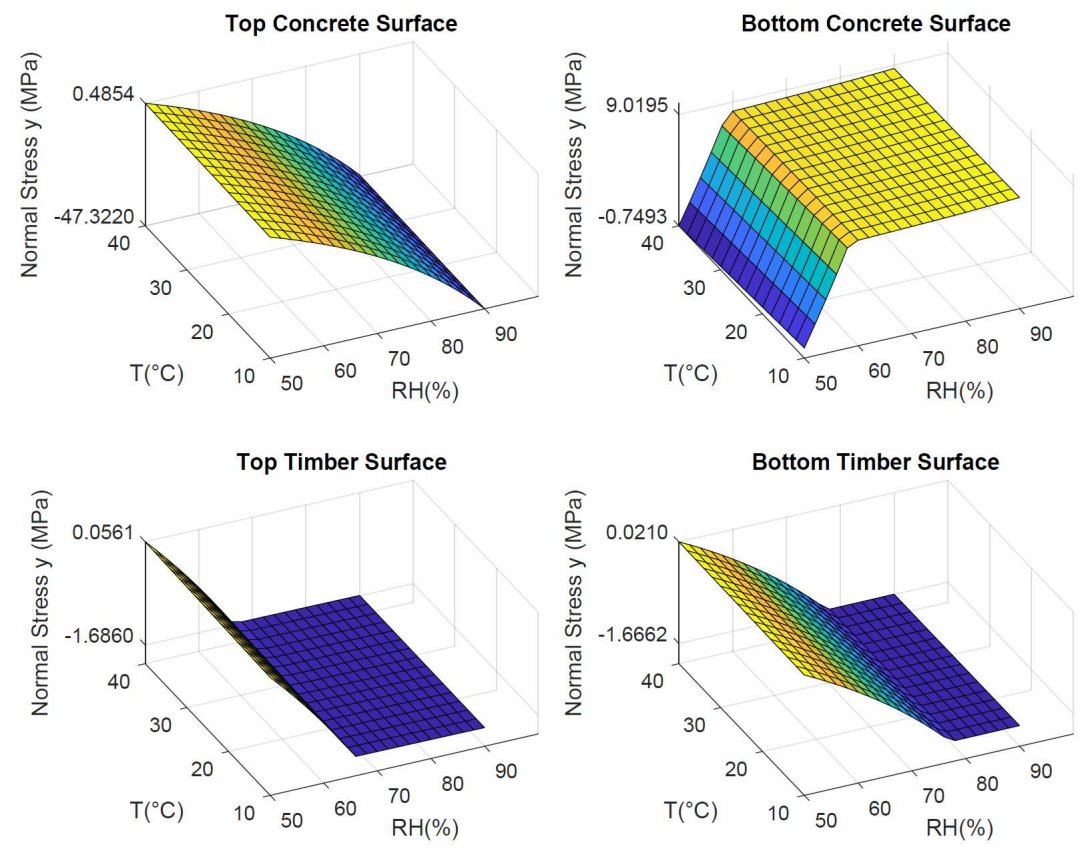

Fig. 4. Normal stress in timber-concrete composite cross-section in $y$-direction due to thermal $(\mathrm{T})$ and humidity $(\mathrm{RH})$ changes of the environment.

\section{Conclusion}

Within the project, preliminary test specimens were prepared in order to investigate the behavior of TCC panels in changing humidity and temperature environmental conditions. The measurement will be carried out in an air-conditioned chamber under controlled environmental conditions with minimizing the influence of mechanical stress and drying shrinkage of concrete. The deformations of the specimens and strains will be measured. The calculation model for the determination of expected stress and deformation values was prepared. The results will serve as a base for the calibration of measuring equipment.

In the calculation, it was assumed that the temperature of the specimens is equal to the environment temperature and the specimens were placed long enough in an environment with constant parameters. In the next study will the real humidity and temperature behavior in cross-section considered using diffusion and thermal laws. The presented calculation model will be used to predict the behavior of multilayer cross-laminated timber-concrete composite specimens in changing environmental conditions.

This work was supported by the Scientific Grant Agency of the Ministry of Education of Slovak Republic and the Slovak Academy of Sciences under Projects VEGA 1/0374/19.

\section{References}

1. A.A. Chiniforush, A. Akbarnezhad, H. Valipour, S. Malekmohammadi, Con. and Build. Mat., 207, 70-83, (2019) 
2. A.A. Chiniforush, H. Valipour, A. Akbarnezhad, Con. and Build. Mat., 224, 10401055, (2019)

3. Rindler, A., Vay, O., Hansmann, C. et al., Wood Sci Techn. 51, 969-996, (2017)

4. L. Eisenhut, W. Seim, S. Kühlborn, Eng. Struct., 125, 167-178, (2016)

5. V. Bajzecerová, J. Kanócz, Proc. Eng., 156, 32-39, (2016)

6. Product data sheet, Sikadur-32 normal, (2017)

7. EN 12390, (2013)

8. EN 1992-1-1, (2015)

9. $\mathrm{EN} \mathrm{408,} \mathrm{(2013)}$

10. EN 338, (2010)

11. T. Toratti, Creep of Timber Beams in Variable Environment (PhD thesis, 1992) 